\title{
Ophthalmic artery chemosurgery for retinoblastoma: an initial 3-year experience from two major institutes in Egypt
}

\author{
Moustafa H Othman', Farouk Hassan², Hamdy M Ibrahim', Eman Aboelhamd Ahmed', George Yassa², \\ Mohamed S Abdel-Rahman³, Mahmoud F. Rateb ${ }^{3}$, Khaled F Riad', Eman B Kamaleldeen ${ }^{5}$, \\ Mohamed Abou Bakr Mohamed ${ }^{5}$, Shimaa Abbas Hassan ${ }^{6}$, Amr M Thabet ${ }^{6}$, Saied Metwaly Elsawy, \\ Rasha Ahmed Hamed ${ }^{6}$, Ahmed Said Imbaby ${ }^{6}$ and Radwa Kamel Soliman ${ }^{1 *}$ (D)
}

\begin{abstract}
Background: Intra-arterial chemotherapy has shown promising results and improved the prognosis of retinoblastoma in the developed countries. Here, we aim to report our initial experience, in Egypt, in the treatment of all stages of naive retinoblastoma with ophthalmic artery chemosurgery (OAC), using melphalan.

Results: The technique was successful in 23 out of 26 eyes. Overall, a total of 63 treatment sessions were performed. Ophthalmic artery catheterization was performed in 59 treatment sessions, whereas middle meningeal artery catheterization was performed in 4 treatment sessions. Adequate tumor control was achieved in 95.6\%. Progression has developed in one eye after the third OAC session. The mean follow-up period was 18.5 months. Recurrence of the main tumor as well as vitreous and subretinal seeds was reported in one eye after 19-month duration. A globe salvage rate of $91.3 \%$ was attained. No metastasis was recorded, and all patients were alive within the stated follow-up period.
\end{abstract}

Conclusion: A high globe salvage rate along with metastasis free survival and mild complications were achieved. Therefore, our initial experience with OAC in primary retinoblastoma proved to be safe and effective.

Keywords: Developing countries, Retinoblastoma, Ophthalmic artery chemosurgery, Melphalan

\section{Background}

Retinoblastoma is the most common pediatric intraocular neoplasm. It remains a significant health problem, particularly in the developing countries [1]. For both unilateral and bilateral diseases, enucleation used to be the main treatment strategy to cure patients and maintain their survival [2]. Yet, this was at the expense of the globe and vision salvage. In more advanced stages, external beam radiation was the alternative treatment procedure that provided globe salvage [3]. This was, however,

\footnotetext{
* Correspondence: Radwa.Soliman@yahoo.co.uk

'Department of Diagnostic and interventional Radiology, Assiut University Hospitals, Faculty of Medicine, Assiut University, P.O. 71515, Assiut, Egypt Full list of author information is available at the end of the article
}

associated with a high rate of second cancer which, in most cases, might have been more fatal than the retinoblastoma [4]. Therefore, systemic intravenous chemotherapy was proposed to reduce the harmful effect of radiotherapy [5] and was frequently used in combination with other focal therapies such as laser or cryotherapy. Some major systemic complications, however, were associated with systemic chemotherapy such as acute myeloid leukemia and neutropenia [6]. Intra-arterial chemotherapy through the carotid artery was introduced early to save the globe and to minimize the radiation exposure and the systemic side effects [7]. The regimen has been modified afterward, to include selective ophthalmic artery infusion chemotherapy, which has been 
developed by the Japanese $[8,9]$. Eventually, the superselective ophthalmic artery chemotherapy, which is also known as ophthalmic artery chemosurgery (OAC), has introduced by Abramson et al. [10].

The use of OAC has been increased, gradually, to be the first choice of retinoblastoma treatment in the developed countries. Consequently, the enucleation rate has been reduced from 95 to about 10\% [11] with the estimated survival rate of retinoblastoma exceeds $95 \%$ in the developed countries [12]. OAC was implemented, however, in a small percent of low- and middle-income countries [1]. Thus, the enucleation rate, in such regions, remains high and ranges from 50 to $87.6 \%$, with estimated survival rate of retinoblastoma reaches about $60 \%$ in Asia and about 30\% in Africa [12].

Here, we introduce our OAC experience in Egypt. Namely, we report our 3 years initial experience for the treatment of early and advanced naive retinoblastoma with $\mathrm{OAC}$, in two major referral centers in Egypt.

\section{Methods \\ Patients}

A prospective study, included patients with newly diagnosed retinoblastoma undergoing $\mathrm{OAC}$, was conducted from January 2016 till March 2019. The study was performed in collaboration between Assiut University Hospital and El- Sheikh Zayed Hospital after obtaining patients' written consents (from parents) and approval from the institutional ethics committees. Both hospitals represent tertiary referral centers, both in the south and north of Egypt. Patients were referred to our neurointerventional suites for OAC after the discussion in the multidisciplinary meetings (including ophthalmologists, pediatric oncologists, diagnostic, and interventional neuro-radiologists). Three patients were referred to us from other Middle East areas (Yemen, Libya, and Sudan). Inclusion criteria included patients who received no prior treatment, the presence of unilateral or bilateral diseases, and any stage of the disease except patients with neovascular glaucoma and anterior chamber invasion. Exclusion criteria further included patients in which the disease can be totally controlled with focal therapy such as laser ablation, cryotherapy, and brachytherapy as well as patients with optic nerve involvement and those with orbital or metastatic diseases. In addition, patients who had abnormal coagulopathy renal or hepatic impairment were excluded. Therefore, a total number of 26 eyes, 19 patients (age ranges 2-48 months) were included in this study.

\section{Technique}

OAC procedures were performed at the angiography suites under general anesthesia. Intravenous heparin (100 UI/kg) was administered as a systemic anticoagulant. A femoral artery puncture was performed at the right side, and a four-French arterial sheath was inserted into the femoral artery. A four-French (vertebral) guide catheter, supported with a 0.035 -inch hydrophilic (Terumo) guidewire was then placed through the sheath to reach the targeted internal carotid artery (ICA), under fluoroscopic guidance. Non-ionic iodine contrast media was injected, and serial angiograms were taken to visualize the cerebral and orbital vascular anatomy. A super-selective catheterization of the ophthalmic artery (OA) was then performed (Fig. 1) via a 1.5 French micro-catheter (Marathon, EV3-Medtronic, USA), supported by either 0.008 in. (Mirage, EV3-Medtronic, USA) or $0.012 / 0.014 \mathrm{in}$. (Traxcess, Microvention, USA) micro-guidewires, and contrast media was injected to confirm the appropriate catheter position and to detect the choroidal blush. If there was no adequate choroidal blush after OA catheterization or even if the OA was not well visualized after ICA catheterization, catheterization of the middle meningeal artery (MMA) through the external carotid artery (ECA) was achieved. In case of bilateral retinoblastoma, tandem technique, previously described by Abramson et al. [13] was performed.

All patients in the current study received melphalan as a single chemotherapeutic drug for OAC. Preparation was performed only after the catheterization of OA. The dose was adjusted according to the age, size of the globe, and the territory infused. Body weight was, particularly, taken into consideration to estimate the toxic dose, $<0.48$ $\mathrm{mg} / \mathrm{kg}$. Melphalan was diluted in $30 \mathrm{ml}$ saline and infused via pulsatile injection, over $30 \mathrm{~min}$, to insure homogenous delivery of the drug. After the infusion, an angiogram was taken to rule out complications related to the procedure such as vasospasm, vascular dissection, or embolism. The catheter and the sheath were then removed, and femoral artery hemostasis was obtained by manual compression at the puncture site. Patients were then awakened and kept under observation for $24 \mathrm{~h}$.

\section{Sessions}

Patients were scheduled to obtain repeated sessions, whenever required, in order to achieve adequate tumor control. Repeated sessions were performed in 3 to 4 weeks interval. At any stage, whenever the residual disease can be controlled by any adjuvant focal therapy, at the discretion of the ophthalmologist, the appropriate therapy was given.

\section{Response assessment}

The response was recorded after the ophthalmological evaluation. Complete regression (CR) was assigned if there was no evidence of a viable tumor or any viable seeds. Partial regression (PR) was assigned whenever 


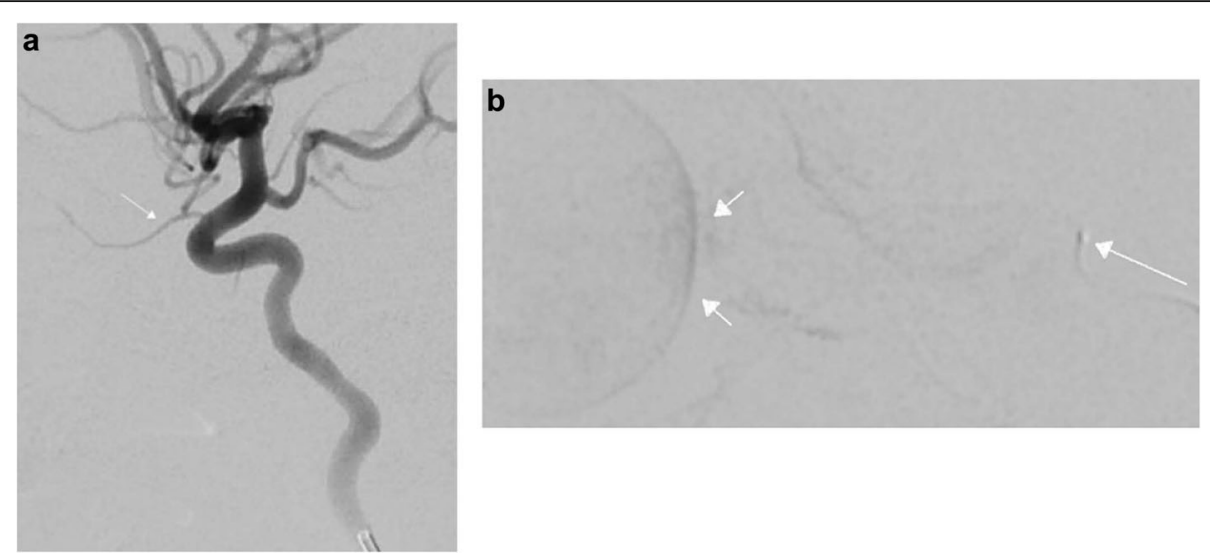

Fig. 1 a ICA angiogram with OA is shown (arrow). b Catheterization of the OA, with catheter tip noted inside its ostium (long arrow) and an adequate choroidal blush was obtained (two short arrows)

there was a reduction in the size of the tumor or in the percent of the viable seeds. Bad response was assigned when changes remain persistent after 2 sessions or if a progression in the tumor size and or seeds was recorded after any session.

\section{Follow-up}

Initially, onco-pediatric evaluation was performed within 7-10 days after each session, whereas ophthalmological evaluation was performed before the initial session and 3 weeks after each session. Follow-up was then continuous at 3 months interval (or earlier whenever required by the pediatric oncologist or the ophthalmologist).

Ophthalmological evaluation included external examination, ocular motility assessment, and complete fundus examination (using indirect ophthalmoscope, ultrasound and, whenever possible, Retcam). It aimed to assess the response of the tumor to the $\mathrm{OAC}$, i.e., the tumor size, the presence and extent of the subretinal/vitreous seeds, distance of the tumor from the optic disc, and fovea as well as the associated retinal detachment. Additionally, it aimed to assess the recurrence as well as the ocular and periocular complications.

Onco-pediatric evaluation included the clinical assessment and the hematological investigation. It aimed to assess the general condition, toxicity from chemotherapy, systemic complications, and patient survival. MRI of the brain and orbit was performed every 6 months, or at shorter interval whenever required, to assess the extraocular extension, any associated pineal, or suprasellar diseases (trilateral or quadrilateral retinoblastomas) and to detect the metastasis.

Eventually, our analysis consisted of primary and secondary measures. The primary measures included evaluation of the success of the technique, the response to OAC sessions, and complications related to the procedure, whereas the secondary measures included assessment of the recurrence, metastasis, and patient survival.

\section{Results \\ The primary measures \\ Success of the technique and number of the sessions}

OAC was successful in 23 out of 26 eyes. Catheterization of OA failed, however, in 3 eyes, due to the sharp angle along with the small ostium of OA, even after reshaping the tip of guidewire to fit the OA. In 2 out of those, it failed in the first session. Yet, in one eye, catheterization was successful in the first session but not in the second session. Therefore, 23 eyes of 16 patients were included in our analysis. Details of patients' characteristics are demonstrated in (Table 1).

The number of OAC sessions received by each eye ranged from 1 to 4 , with four eyes underwent four OAC sessions, ten eyes underwent three sessions while eight eyes underwent 2 sessions, and only one eye underwent one session. Thus, a total of 63 sessions were ultimately performed. OA catheterization was performed in 59 sessions (shaping the tip of the guidewire to fit the sharp angle of OA was achieved in two eyes) (Fig. 2), while MAA catheterization was performed in 4 sessions (due to reflux of the contrast back to the ICA (Fig. 3) and due to non-visualized OA after ICA catheterization).

\section{Response to OAC treatments}

Adequate tumor control was achieved in 22 out of 23 eyes (95.66\%). Fifteen eyes (65.2\%) showed CR after the OAC treatments. Eight eyes (34.8\%) showed PR after the $\mathrm{OAC}$ sessions and were amenable for adjuvant therapy, either laser $(n=6)$ or plaque brachytherapy $(n=2)$. On the other hand, $(4.34 \%)$ one eye (stage D) showed a progression of the main solid tumor after the third session and enucleation was performed. 
Table 1 Characteristic of retinoblastoma patients received OAC treatments between January 2016 and March 2019

\begin{tabular}{ll}
\hline Features & Patient characteristics \\
\hline $\begin{array}{l}\text { Number of patients included } \\
\text { Number of eyes }\end{array}$ & 16 patients \\
Age & 23 eyes \\
& Range ( $2-48$ months) \\
& Mean age $=11.1$ months \\
Sex & 8 males, 8 females \\
Laterality & Unilateral, 9 patients \\
& Bilateral, 7 patients \\
Family history & Positive, 6 patients \\
& Negative, 10 patients \\
Stage of the disease according & Stage B $=8$ eyes (34.8\%) \\
to the International Classification & Stage C $=7$ eyes (30.5\%) \\
of Retinoblastoma & Stage D $=5$ eyes (21.7\%) \\
& Stage $E=3$ eyes (13\%) \\
& Range (9-36 months) \\
Follow-up period & Mean $=18.5$ months \\
\hline
\end{tabular}

\section{Complications}

The main ocular complications included ophthalmic artery stenosis $(n=4)$ and localized chorioretinal atrophy $(n=3)$. The periocular complications included temporary eyelid edema $(n=4)$ and periorbital hyperemia $(n=2)$. The systemic complications mainly included vomiting $(n=15)$, transient neutropenia $(n=2)$, but no one required a blood transfusion, and reduced tidal volume $(n=2)$ that has been treated with intravenous epinephrine, after pausing catheterization. No anaphylactoid reaction had been recorded and no major intracranial complications such as ischemic stroke, seizure, or any neurological deficits.

\section{The secondary measures}

The mean follow-up duration is equal to 18.5 months (ranges 9-36 months) with only one eye has been followed up for less than 12 months ( 9 months).

\section{Recurrence and globe salvage}

Only one eye (4.3\%) showed orbital recurrence. A 4year-old female with bilateral disease has developed the recurrence in the right eye (stage $\mathrm{E}$, at time of presentation). The patient received four sessions of OAC treatments and later received laser ablation therapy, then showed a complete resolution. Yet, recurrence of the main solid tumor, with subretinal and vitreous seeds was recorded, during a follow-up duration of 19 months, and enucleation was then performed.

Overall, out of 23 eyes, two eyes underwent enucleation (In one eye, enucleation was performed after a recurrence of the main tumor, while in the other eye enucleation was performed due to progression of the disease even after the third OAC session). Therefore, the globe salvaged has been achieved in $91.3 \%$ of our population, during a mean follow-up duration of 18.5 months.

\section{Metastasis and patient survival}

No reported case of metastasis or death $(100 \%$ metastasis free survival) during a mean follow-up period of 18.5 months.
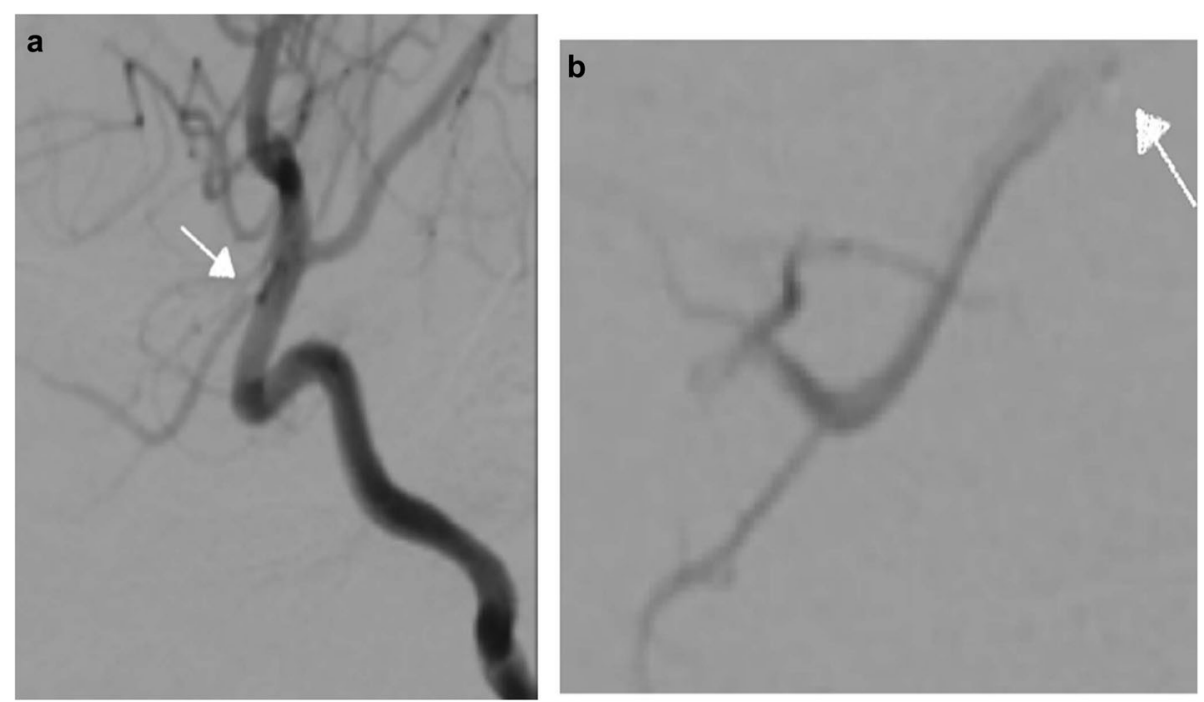

Fig. 2 a ICA angiogram with noted sharp angle of the OA (arrow). b Catheterization of the OA was successful after reshaping of the guidewire. The tip of the micro-catheter is noted inside the ostium (arrow) 

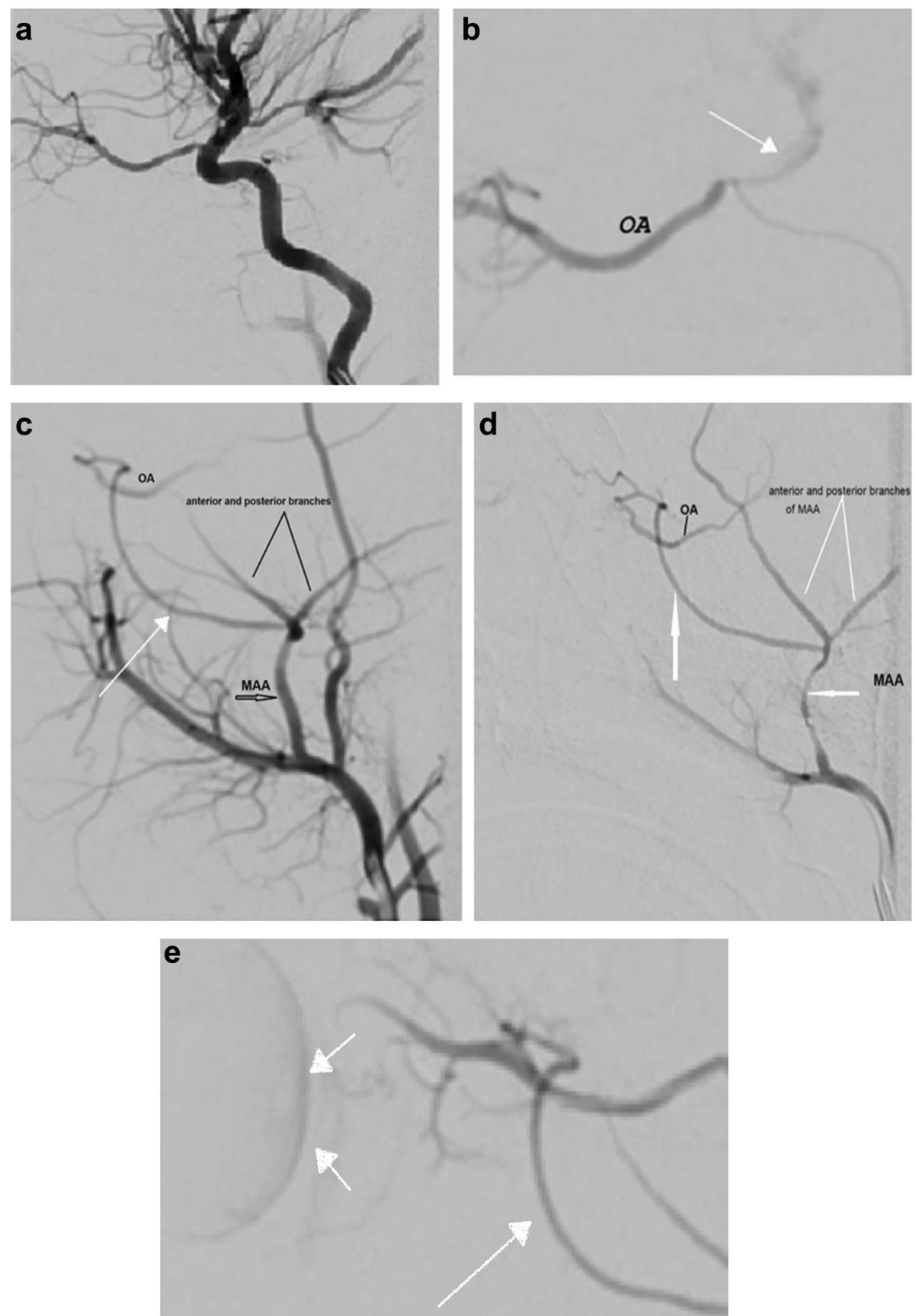

Fig. 3 a Angiogram of the ICA. $\mathbf{b}$ A reflux of the contrast back from the OA to ICA is noted (white arrow). $\mathbf{c}$ ECA angiogram was then performed and revealed an anastomotic branch between MMA and OA (white arrow). d MAA angiogram: the anastomosis between MAA and OA (long vertical arrow) is shown again. e Zoomed image, an adequate choroidal blush (two short arrows) was obtained, through the anastomotic branch (long arrow), after MAA catheterization

\section{Discussion}

In the current study, we evaluated our initial experience in Egypt to implement OAC for the treatment of both unilateral and bilateral naive retinoblastoma patients. About $34.7 \%$ presented with advanced stage and the youngest patient was 2 months old. At such young age, OAC might be challenging. Therefore, only few reports have included this age while applying OAC [14-16].

Catheterization was successful in 23 eyes out of 26, with a total of 63 sessions, in the current study. The main reason why the technique failed, in three of our cases, was the sharp angle of the OA which hindered the proper catheterization of its ostium. In such cases, 
shaping the tip of the guidewire was performed to fit the OA ostium, as described previously [17, 18]. Despite being successful in two eyes of our cases, it failed in the other three eyes. Catheterization, however, was not further forced to avoid OA injury. An alternative approach to overcome the sharp angle of OA was by applying the temporary balloon occlusion technique to the ICA [8, 19]. Yet, we have not apply this maneuver to avoid the risk of thromboembolic complications and to avoid dilution of melphalan over a larger volume of the blood [17, 20]. Another difficulty we encountered here was the reflux of the contrast media back to the ICA. Such reflux usually occurs as a result of a hemodynamic flow imbalance with inversion of the blood flow through multiple collaterals between OA and the MMA [17]. The presence of the catheter inside the OA ostium has been thought to be a trigger factor for this hemodynamic disturbance with activation of the collaterals [17, 21]. Catheterization of the MMA via ECA approach, as previously proposed $[17,19]$, was successfully performed in such cases.

Initially, tumor control has been achieved in $95.6 \%$ of the treated eyes. While $65.2 \%$ revealed CR after OAC sessions, $34.8 \%$ revealed $\mathrm{CR}$ only after additional adjuvant therapy. We relied on melphalan as a single chemotherapeutic drug in treating our patients. It is the primary drug used in OAC and has been shown to be the most powerful one $[10,22]$. Other studies have used both single and multiple drug regimen, e.g., carboplatin and topotecan in combination with melphalan $[18,19$, 23-26].Combined drug therapy was particularly employed in more advanced cases [23-25] or in tandem therapy [22].

In keeping with our data, Tuncer et al. revealed that, of those who had been treated only with melphalan during $\mathrm{OAC}$, only one eye out of 17 retinoblastomas, with stage D, did not reveal CR [27]. Similarly, other studies achieved high rates of tumor control, even in advanced stages, when relied only on melphalan for OAC [28-30]. On the other hand, Thampi et al. achieved good tumor response only in less advanced stages but not in the more advanced retinoblastomas, when used melphalan as a single agent for OAC [31].

In the current study, only one eye (4.3\%) developed a recurrence after 19 months. A tumor resistance to the chemotherapy has been recorded previously, particularly, when a single agent is used [27, 32]. Such a resistance might be a reason for the recurrence in our case. Contrast to our results, different studies revealed a higher rate of recurrence. Shield et al. reported a recurrence rate of $19 \%$, after OAC in primary retinoblastomas, including all stages, within 24 months [33]. Furthermore, Tuncer et al, in a 4-year experience, reported a recurrence rate of $29 \%$ after OAC in group D retinoblastomas, within the first year [27]. The relatively small sample size, particularly, with the small number of advanced retinoblastomas, in addition to the short follow-up duration, may explain our lower recurrence rate. Our results, however, are in agreement with other studies in which low recurrence rates were recorded after OAC, even in advanced cases [30, 34]. In fact, there were notable variations regarding the disease stage, the number of the eyes received treatment, as well as the follow-up period among the different studies which might, in part, contributed to these results discrepancy. In this context, in 10 years' experience study conducted by Francis et al. investigating the risk factors associated with recurrence after $\mathrm{OAC}$, they found that in addition to using single chemotherapeutic agent, increase the number of chemotherapeutic agents used in combination, bridge therapy, as well as presence of vitreous seeds at the first visit, older age at the time of presentation, and longer interval between OAC sessions (more than 4 weeks) are all significantly associated with high recurrence rate. The latter was the only factor significantly associated with a high recurrence rate if OAC was accompanied by intravitreal chemotherapy injection. Furthermore, they revealed that eyes which did not develop recurrence in the first year had only $8 \%$ risk of recurrence by the 2nd year [32].

In the present study, enucleation was performed due to disease progression in one eye and due to recurrence of the disease in another eye. Eventually, we were able to attain a high globe salvage rate $(91.3 \%)$. Such results are consistent with other studies $[28,35]$ in which high globe salvage rates were achieved, and further emphasizing the efficacy OAC in retinoblastoma.

Fortunately, none of our patients developed metastasis and all of them were alive within the stated follow-up period (mean $=18.5$ months). In parallel with our data, other studies showed no metastasis developed after OAC $[18,27,33,36]$. Others reported a low incidence of metastasis [11]. Nevertheless, different studies worldwide revealed that no patient has died from the metastatic disease after OAC [11, 30, 31].

The main ocular complications that we encountered in the current study were ophthalmic artery stenosis and chorioretinal atrophy. The ophthalmic artery narrowing was detected by fluoroscopy, in four eyes, in the late sessions and is likely caused by catheter injury or by the toxic effect of chemotherapy to the vascular endothelium. Localized chorioretinal atrophy was detected in three eyes after either the third or fourth session. It is most likely secondary to the toxic effect of the chemotherapy from earlier sessions, since it takes several months to progress. Previous studies also showed low rates of chorioretinal atrophy [27, 29, 33, 37]. In line with other studies [19, 27], other minor periocular 
complications such as lid edema and periorbital hyperemia have been reported in our study yet, they were resolved shortly afterward. A transient neutropenia, which is related to the chemotherapy toxicity, has been reported in our series yet, none of our patient required blood transfusion. In addition, reduced tidal volume was evident twice in the current study. Similarly, it has been shown previously in some patients during OAC $[38,39]$ and has been assumed to evolve secondary to catheter placing in the ICA or OA orifice [40]. In such cases, reduced tidal volume was managed by suspending the catheterization and elevating the airway pressure. Immediate intravenous epinephrine would aid to avoid further hemodynamic collapse [40].

One of our limitations was the lack of availability of other chemotherapeutic drugs during the time of our study. Thus, we relied only on melphalan even in the advanced stages or in tandem therapy. In our future OAC treatments, combined drug therapy will be included. The small sample size is another limitation of this study. Being an initial experience that is less accustomed by clinicians and parents may be the reason behind this.

\section{Conclusion}

In summary, we were able to achieve a high rate of globe salvage with a minimal rate of complications and at the same time, $100 \%$ metastasis free survival was maintained. Therefore, our study provides promising results for treating both early and advanced stages of retinoblastoma, safely, in the developing countries, particularly in Egypt.

\section{Abbreviations \\ CR: Complete regression; ECA: External carotid artery; ICA: Internal carotid artery; OA: Ophthalmic artery; OAC: Ophthalmic artery chemosurgery; MAA: Middle meningeal artery; PR: Partial regression}

\section{Acknowledgements}

We are grateful to Dr. David H. Abramson for his guidance during the time of this study.

\begin{abstract}
Authors' contributions
EAA, MHO, FH, RKS, and HMI were responsible for the study conception, design, and data analysis. $\mathrm{MHO}, \mathrm{FH}, \mathrm{HMI}$, and $\mathrm{GY}$ performed the procedures. RKS wrote the manuscript. MSA, MFR, KFR, EBK, and MAM were responsible for the clinical and ophthalmological examinations as well as for the followup. SAH, AMT, SME, RAH, and ASI were responsible for intra- and postoperative monitoring. All authors substantially revised the manuscript and approved the submission.
\end{abstract}

\section{Funding}

This study was not supported by any funding.

\section{Availability of data and materials}

The datasets generated during and/or analyzed during the current study are available from the corresponding author on reasonable request.

\section{Ethics approval and consent to participate}

The study was approved by the institutional ethical committee (Faculty of Medicine, Assiut University Ethical Committee), and the committee's reference number is not applicable. Written informed consent was obtained from all individual participants included in the study.

\section{Consent for publication}

All patients included in this research gave written informed consent to publish the data contained within this study.

\section{Competing interests}

The authors declare that they have no conflict of interest.

\section{Author details}

'Department of Diagnostic and interventional Radiology, Assiut University Hospitals, Faculty of Medicine, Assiut University, P.O. 71515, Assiut, Egypt. ${ }^{2}$ Department of Diagnostic and interventional Radiology, Faculty of Medicine, Cairo University, Cairo, Egypt. ${ }^{3}$ Department of Ophthalmology, Faculty of Medicine, Assiut University Hospitals, Assiut, Egypt. ${ }^{4}$ Department of Pediatric Oncology, South Egypt cancer Institute, Assiut University, Assiut, Egypt. ${ }^{5}$ Department of Pediatrics, Faculty of Medicine, Assiut University Hospitals, Assiut, Egypt. ${ }^{6}$ Department of Anesthesia and Intensive care,Faculty of Medicine, Assiut University Hospitals, Assiut, Egypt.

Received: 28 February 2020 Accepted: 5 May 2020

Published online: 18 May 2020

\section{References}

1. Grigorovski N, Lucena E, Mattosinho C, Parareda A, Ferman S, Catalá J, Chantada G (2014) Use of intra-arterial chemotherapy for retinoblastoma: results of a survey. Int J Ophthalmol 7(4):726

2. Abramson DH (2014) Retinoblastoma: saving life with vision. Annu Rev Med 65:171-184

3. Scott IU, Murray TG, Feuer WJ, Van Quill K, Markoe AM, Ling S et al (1999) External beam radiotherapy in retinoblastoma: tumor control and comparison of 2 techniques. Arch Ophthalmol 117(6):766-770

4. Eng C, Li FP, Abramson DH, Ellsworth RM, Wong FL, Goldman MB et al (1993) Mortality from second tumors among long-term survivors of retinoblastoma. J Natl Cancer Inst 85(14):1121-1128

5. Shields CL, De Potter P, Himelstein BP, Shields JA, Meadows AT, Maris JM (1996) Chemoreduction in the initial management of intraocular retinoblastoma. Arch Ophthalmol 114(11):1330-1338

6. Gombos DS, Hungerford J, Abramson DH, Kingston J, Chantada G, Dunkel IJ et al (2007) Secondary acute myelogenous leukemia in patients with retinoblastoma: is chemotherapy a factor? Ophthalmology 114(7):1378-1383

7. Reese AB, Hyman GA, Forrest AW (1958) The treatment of retinoblastoma by $x$-ray and triethylene melamine. AMA Arch Ophthalmol 60(5):897-906

8. Yamane T, Kaneko A, Mohri M (2004) The technique of ophthalmic arterial infusion therapy for patients with intraocular retinoblastoma. Int J Clin Oncol 9(2):69-73

9. Mohri M (1993) The development of a new system of selective ophthalmic arterial infusion for the patients of intraocular retinoblastoma (in Japanese). Keio Igaku (J Keio Med Soc) 70:679-687

10. Abramson DH, Dunkel IJ, Brodie SE, Kim JW, Gobin YP (2008) A phase I/II. study of direct intraarterial (ophthalmic artery) chemotherapy with melphalan for intraocular retinoblastoma: initial results. Ophthalmology 115(8):1398-1404

11. Abramson DH, Fabius AW, Issa R, Francis JH, Marr BP, Dunkel IJ, Gobin YP (2015) Advanced unilateral retinoblastoma: the impact of ophthalmic artery chemosurgery on enucleation rate and patient survival at MSKCC. PLoS One 10(12):e0145436

12. Rashid R et al (2019) Management of retinoblastoma in developing country: a study of 84 cases. EC Ophthalmology 10(2):70-78

13. Abramson DH, Dunkel IJ, Brodie SE, Marr B, Gobin YP (2010) Bilateral superselective ophthalmic artery chemotherapy for bilateral retinoblastoma: tandem therapy. Arch Ophthalmol 128(3):370-372

14. Magan T, Khoo CT, Jabbour PM, Shields CL (2017) Intraarterial chemotherapy for retinoblastoma in a 2-month-old infant. Retin Cases Brief Rep 11(1):24-26

15. Chen Q, Zhang B, Dong Y, Mo X, Zhang L, Xia J et al (2019) Intraarterial chemotherapy as primary or secondary treatment for infants diagnosed with advanced retinoblastoma before 3 months of age. BMC Cancer 19(1):693 
16. Chen M, Zhao J, Xia J, Liu Z, Jiang H, Shen G et al (2016) Intra-arterial chemotherapy as primary therapy for retinoblastoma in infants less than 3 months of age: a series of 10 case-studies. PLoS One 11(8)

17. Bertelli E, Leonini S, Galimberti D, Moretti S, Tinturini R, Hadjistilianou T et al (2016) Hemodynamic and anatomic variations require an adaptable approach during intra-arterial chemotherapy for intraocular retinoblastoma: alternative routes, strategies, and follow-up. Am J Neuroradiol 37(7):1289-1295

18. Venturi C, Bracco S, Cerase A, Cioni S, Galluzzi P, Gennari P et al (2013) Superselective ophthalmic artery infusion of melphalan for intraocular retinoblastoma: preliminary results from 140 treatments. Acta Ophthalmol 91(4):335-342

19. Klufas MA, Gobin YP, Marr B, Brodie SE, Dunkel IJ, Abramson DH (2012) Intra-arterial chemotherapy as a treatment for intraocular retinoblastoma: alternatives to direct ophthalmic artery catheterization. Am J Neuroradiol 33(8):1608-1614

20. Stenzel E, Göricke S, Temming P, Biewald E, Zülow S, Göbel J et al (2019) Feasibility of intra-arterial chemotherapy for retinoblastoma: experiences in a large single center cohort study. Neuroradiology 61(3):351-357

21. Marr BP, Hung C, Gobin YP, Dunkel IJ, Brodie SE, Abramson DH (2012) Success of intra-arterial chemotherapy (chemosurgery) for retinoblastoma: effect of orbitovascular anatomy. Arch Ophthalmol 130(2):180-185

22. Abramson DH, Marr BP, Francis JH, Dunkel IJ, Fabius AW, Brodie SE et al (2016) Simultaneous bilateral ophthalmic artery chemosurgery for bilateral retinoblastoma (tandem therapy). PLoS One 11(6)

23. Abramson DH, Dunkel IJ, Brodie SE, Marr B, Gobin YP (2010) Superselective ophthalmic artery chemotherapy as primary treatment for retinoblastoma (chemosurgery). Ophthalmology 117(8):1623-1629

24. Abramson DH, Daniels AB, Marr BP, Francis JH, Brodie SE, Dunkel IJ, Gobin YP (2016) Intra-arterial chemotherapy (ophthalmic artery chemosurgery) for group D retinoblastoma. PLoS One 11(1)

25. Shields CL, Manjandavida FP, Lally SE, Pieretti G, Arepalli SA, Caywood EH et al (2014) Intra-arterial chemotherapy for retinoblastoma in 70 eyes: outcomes based on the international classification of retinoblastoma. Ophthalmology 121(7):1453-1460

26. Hua J, Gang S, Yizhou J, Jing Z (2018) Intra-arterial chemotherapy as second-line treatment for advanced retinoblastoma: a 2-year single-center study in China. J Cancer Res Ther 14(1):106

27. Tuncer S, Sencer S, Kebudi R, Tanyıldız B, Cebeci Z, Aydın K (2016) Superselective intra-arterial chemotherapy in the primary management of advanced intra-ocular retinoblastoma: first 4-year experience from a single institution in Turkey. Acta Ophthalmol 94(7):e644-e651

28. Munier FL, Mosimann P, Puccinelli F, Gaillard MC, Stathopoulos C, Houghton $S$ et al (2017) First-line intra-arterial versus intravenous chemotherapy in unilateral sporadic group D retinoblastoma: evidence of better visual outcomes, ocular survival and shorter time to success with intra-arterial delivery from retrospective review of 20 years of treatment. $\mathrm{Br} \mathrm{J}$ Ophthalmol 101(8):1086-1093

29. Ong SJ, Chao AN, Wong HF, Liou KL, Kao LY (2015) Selective ophthalmic arterial injection of melphalan for intraocular retinoblastoma: a 4-year review. Jpn J Ophthalmol 59(2):109-117

30. Muen WJ, Kingston JE, Robertson F, Brew S, Sagoo MS, Reddy MA (2012) Efficacy and complications of super-selective intra-ophthalmic artery melphalan for the treatment of refractory retinoblastoma. Ophthalmology 119(3):611-616

31. Thampi S, Hetts SW, Cooke DL, Stewart PJ, Robbins E, Banerjee A et al (2013) Superselective intra-arterial melphalan therapy for newly diagnosed and refractory retinoblastoma: results from a single institution. Clinical Ophthalmology (Auckland, NZ) 7:981

32. Francis JH, Levin AM, Zabor EC, Gobin YP, Abramson DH (2018) Ten-year experience with ophthalmic artery chemosurgery: ocular and recurrencefree survival. PLoS One 13(5)

33. Shields CL, Bianciotto CG, Jabbour P, Ramasubramanian A, Lally SE, Griffin GC et al (2011) Intra-arterial chemotherapy for retinoblastoma: report no. 1 , control of retinal tumors, subretinal seeds, and vitreous seeds. Arch Ophthalmol 129(11):1399-1406

34. Yannuzzi NA, Francis JH, Marr BP, Belinsky I, Dunkel IJ, Gobin YP, Abramson DH (2015) Enucleation vs ophthalmic artery chemosurgery for advanced intraocular retinoblastoma: a retrospective analysis. JAMA Ophthalmol 133(9):1062-1066
35. Abramson DH, Marr BP, Brodie SE, Dunkel I, Palioura S, Gobin YP (2012) Ophthalmic artery chemosurgery for less advanced intraocular retinoblastoma: five year review. PLoS One 7(4)

36. Dalvin LA, Kumari M, Essuman VA, Shipa SS, Ancona-Lezama D, LucioAlvarez JA et al (2019) Primary intra-arterial chemotherapy for retinoblastoma in the intravitreal chemotherapy era: five years of experience. Ocul Oncol Pathol 5(2):139-146

37. Wang L, Han M, Zhao J, Wu C, Wang Z, Li J et al (2018) Intra-arterial chemotherapy for unilateral advanced intraocular retinoblastoma: results and short-term complications. Medicine 97(42)

38. Kato MA, Green N, O'Connell K, Till SD, Kramer DJ, Al-Khelaifi M et al (2015) A retrospective analysis of severe intraoperative respiratory compliance changes during ophthalmic arterial chemosurgery for retinoblastoma. Pediatr Anesth 25(6):595-602

39. Phillips TJ, McGuirk SP, Chahal HK, Kingston J, Robertson F, Brew S et al (2013) Autonomic cardio-respiratory reflex reactions and superselective ophthalmic arterial chemotherapy for retinoblastoma. Pediatr Anesth 23(10): 940-945

40. Scharoun $J H_{1}$, Han JH, Gobin YP (2017) Anesthesia for ophthalmic artery chemosurgery. Anesthesiology 126(1):165-172

\section{Publisher's Note}

Springer Nature remains neutral with regard to jurisdictional claims in published maps and institutional affiliations.

\section{Submit your manuscript to a SpringerOpen ${ }^{\circ}$ journal and benefit from:}

- Convenient online submission

- Rigorous peer review

- Open access: articles freely available online

High visibility within the field

- Retaining the copyright to your article

Submit your next manuscript at $>$ springeropen.com 